\title{
CASE REPORT: LAPAROSCOPIC DRAINAGE OF A GIANT SIMPLE LIVER CYST
}

\author{
P McBride, Registrar, T Leese, Consultant Surgeon \\ Royal Lancaster Infirmary
}

\section{INTRODUCTION}

Most simple liver cysts are benign and asymptomatic. If they reach giant proportions, the patient may present with an abdominal mass or pain. Simple aspiration and alcohol injections have proved to be ineffective. Laparoscopic drainage is a safe and effective method of treating these patients. We describe the laparoscopic technique for drainage and fenestration of a symptomatic giant liver cyst.

\section{CASE REPORT}

A 79-year-old female presented with a one-year history of dull right upper quadrant and flank pain and a dragging sensation which she described as a "bag of water". Examination revealed a large right hypochondrial mass. Blood count, liver function tests, hydatid serology and alpha feto protein were all normal. Chest X-ray (Figure 1) demonstrated gross elevation of the right hemi-diaphragm. Ultrasound and CT scan (Figure 2) showed a $24 \mathrm{~cm}$ liver cyst which replaced nearly the entire right lobe of the liver. The cyst displaced the remaining right lobe across the midline, forcing the gallbladder to lie to the left of the midline and the right kidney to lie in the midline at the level of the umbilicus. The appearance was typical of giant simple cyst of the liver.

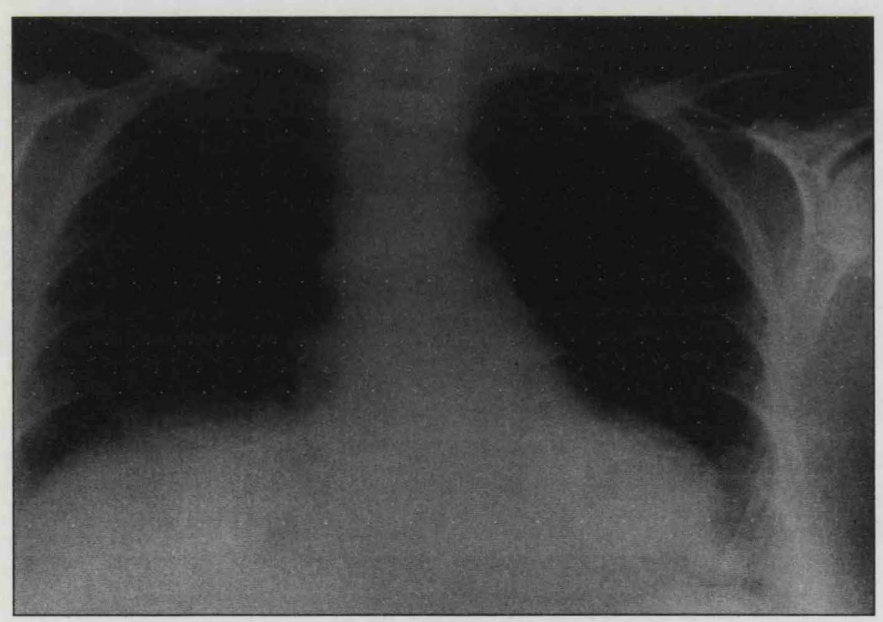

Fig. 1 - Chest X-ray showing marked elevation of the right hemi-diaphragm.

\section{OPERATIVE TECHNIQUE}

$\mathrm{A} \mathrm{CO}_{2}$ pneumoperitoneum was created using a Veres needle at the umbilicus. A zero degree laparoscope was introduced through a $10 \mathrm{~mm}$ port at the umbilicus for initial exploration. Two additional $5 \mathrm{~mm}$ ports and one $10 \mathrm{~mm}$ port were placed in the right upper quadrant and epigastrium. Intracorporeal suction was used to aspirate four litres of cyst fluid. The cutting diathermy was then employed to excise a $15 \mathrm{~cm} \mathrm{x}$ $20 \mathrm{~cm}$ disc of the anterior cyst wall.

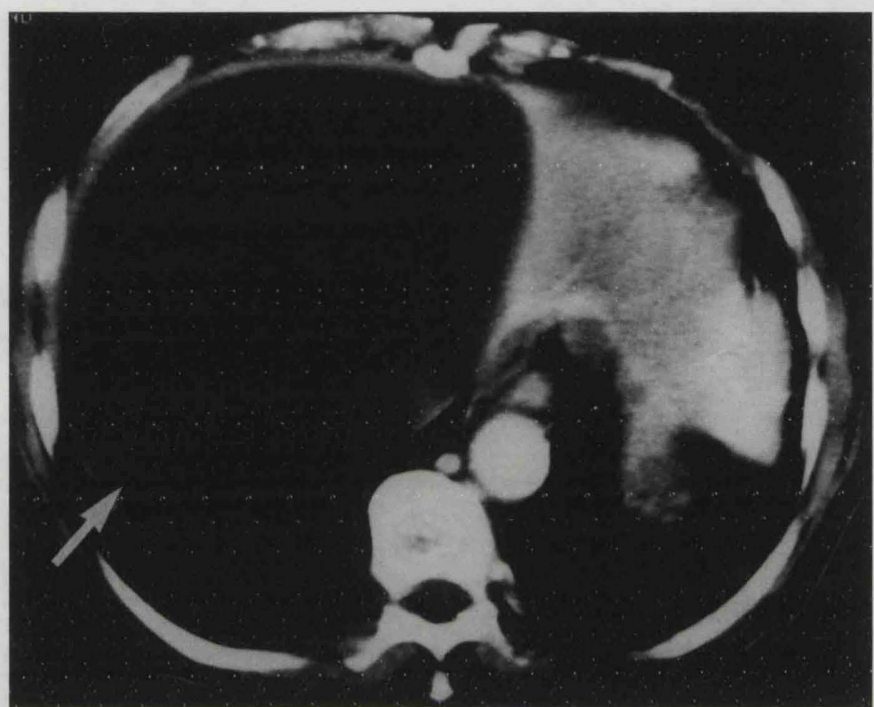

Fig. 2 - CT scan with intravenous contrast showing the giant simple cyst in the right lobe of the liver (arrowed)

\section{FOLLOW-UP}

The patient recovered rapidly from the surgical procedure and was ready for discharge within 24 hours. On follow-up at one month her symptoms had resolved and repeat CT scan showed almost complete resolution of the liver cyst with restoration of normal liver anatomy (Figure 3).

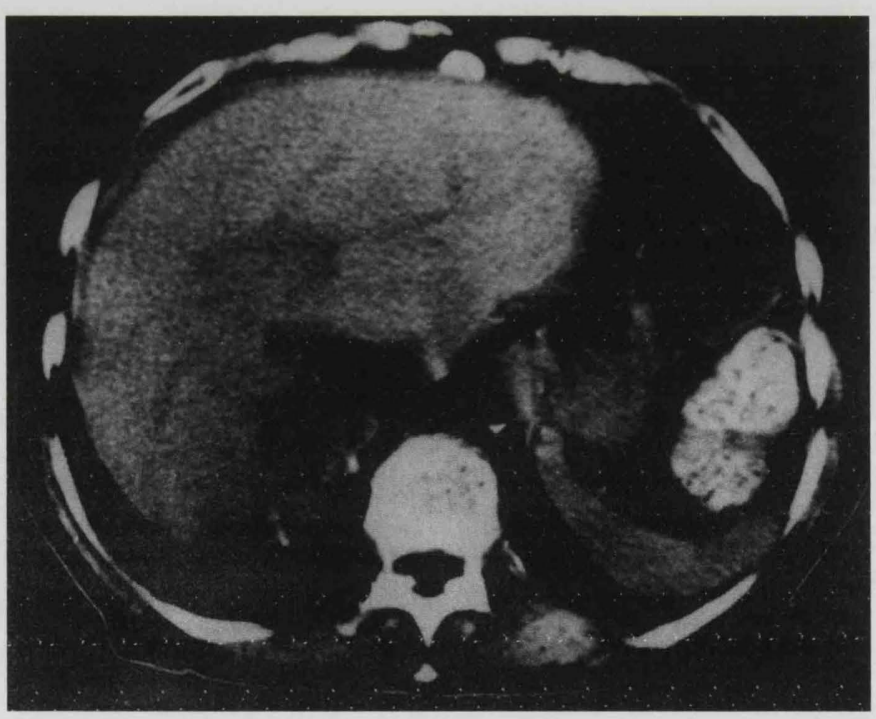

Fig. 3 - Follow-up CT scan at one month showing cyst resolution and restoration of normal hepatic anatomy

\section{DISCUSSION}

The prevalence of simple cysts of the liver is estimated to be about $1 \%$ in the adult population. They are usually small $(<5 \mathrm{~cm})$ and asymptomatic, being picked up as incidental findings on liver imaging. Giant liver cyst tends 
predominantly to affect women over the age of 50. A large cyst may result in atrophy of the involved lobe and hypertrophy of the other lobe. The most common complication is intracystic bleeding which results in the sudden onset of abdominal pain with the rapid enlargement of the cyst $^{(1)}$. Most of these cysts, however, remain asymptomatic. The treatment of choice is surgical fenestration which involves partial excision of the external wall of the cyst $^{(2)}$. Laparoscopic fenestration of giant liver cysts is a safe and effective means to treat symptomatic giant liver cysts. It is more comfortable and has a more rapid recovery time than conventional open surgical fenestration.

\section{REFERENCES}

1 Benhamou JP, Menu Y Surgery of the Liver and Biliary Tract Chapter 83, Non-parasitic cystic diseases of the liver and intrahepatic biliary tree 2nd ed Churchill Livingstone 1994

2 Jones RS Surgery of the Liver and Biliary Tract Chapter 84, Surgical management of non-parasitic liver cysts 2 nd ed Churchill Livingstone 1994

\section{Follower}

My father worked with a horse-plough, His shoulders globed like a full sail strung Between the shafts and the furrow.

The horses strained at his clicking tongue.

An expert. He would set the wing And fit the bright steel-pointed sock. The sod rolled over without breaking. At the headrig, with a single pluck

Of reins, the sweating team turned round And back into the land. His eye

Narrowed and angled at the ground, Mapping the furrow exactly.

I stumbled in his hob-nailed wake, Fell sometimes on the polished sod; Sometimes he rode me on his back Dipping and rising to his plod.

I wanted to grow up and plough, To close one eye, stiffen my arm. All I ever did was follow In his broad shadow round the farm

I was a nuisance, tripping, falling, Yapping always. But to-day It is my father who keeps stumbling Behind me, and will not go away.

Seamus Heaney 